\title{
Co-designing the pedestrian revolution in Muscat
}

\author{
Gustavo De Siqueira* (1) and Amal Al Balushi
}

\begin{abstract}
Rapid growth coupled with the prevailing land allocation system in Oman led to a shift from compact dwellings typologies to detached single-family houses, arranged in monofunctional zoning systems that exclusively rely on cars. Due to the sprawled transformation, authorities are unable to provide new neighborhoods with basic infrastructure and attractive open spaces. Consequently, the level of non-communicable diseases is increasing, making urban regeneration programs promoting active lifestyles in built environments a matter of public health. In our research we explore participative-planning strategies to enhance pedestrian activity within existing neighborhoods and regenerate public spaces. We conducted a quantitative survey using a standard walkability scale and physical maps to identify barriers to pedestrian activity. Subsequently, we employed the data to frame culturally sensitive co-creation workshops, gaining in-depth knowledge to guide future redesign proposals. We found that mosques are walking magnets yet engender contrasting views with regard to walkability; finding solutions to the spatial problems could develop them into walkable cores. We also observed that residents were aware of health problems caused by lack of physical activity and how that links with the built environment they inhabit. They were eager to discuss solutions, including alternative governance models, as long as the process was short and produced immediate small interventions with high-level impact on their surroundings. We employed a fine-grained combination of methods to address sitespecific challenges. Its quantitative data allows the insertion in a broader discourse and the linkage to a large body of research in walkability. Co-creation workshops, especially city games, proved to be a powerful tool to initiate dialogue on complex spatial negotiation, even in societies where participatory approaches do not have a well-established tradition.
\end{abstract}

Keywords: Car-oriented developments, Rapid urbanization, Collaborative design, Walkable neighborhoods

\section{Introduction}

Urbanization is a global process occurring at a pace without precedent. This phenomenon is dramatically affecting cities and metropolitan regions to a greater extent where infrastructure and governance bodies are not well established (UN-HABITAT 2016; United Nations 2015). Traditional planning tools designed to address the challenges posed by this rapidly transforming environment are non-existent, neither is a comprehensive theoretical body available (Bettencourt 2013; Bettencourt et al. 2007). Planning, whenever detached from real life and

\footnotetext{
*Correspondence: gustavo.desiqueira@gutech.edu.om Urban Planning and Architecture Design Department, German University of Technology in Halban, Muscat, Oman
}

realpolitik, will necessarily fail to fulfil its goal: to provide citizens with sustainable, healthy and equitable cities (Flyvbjerg 2003).

In this study, we are looking into ways to address the essential needs of the citizens of Muscat, which is a city witnessing a spatial revolution since the 1970s, radically affecting its landscape but also provoking a shift in its cultural backbone (Majid et al. 2018). We are seeking methods to not only listen to what citizens have to say about their living environments, but also how they would re-shape the existing situation if they were given the chance to do so.

The article starts with a contextualization of Muscat's development from a smaller harbor area and a few geographically separated-tribally-owned-fishermen's 
villages, which were gradually co-urbanized into what is called the Muscat Capital Area (MCA). It further examines how people were (or were not) involved in this process. It describes how the shift from an almost exclusively self-made city towards a completely centralized development happened and how, consequently, the urbanization pressure created a vacuum of competencies.

We examined this phenomenon gradually, from anonymous assessments "from the distance" represented by quantitative tools to more personal community gatherings, thereby gathering information through different layers to help us to gain a deeper understanding. The initial quantitative data highlighted the larger general topics to approach and negotiate in detail at the case-specific community meetings.

Ultimately, we aim to provoke action and informing local planners on the human experience of residents. We are confident that the present methodology can contribute to a significant betterment of the local environment despite the ongoing isolation between and within communities, the broadly spread perception that authorities are the sole providers, and an ambivalent view of the public realm.

\section{Background}

\section{Muscat, an expanding metropolis}

Pre-1970s, Muscat and the rest of Oman's built environment took on a decentralized approach in spatial planning and governance, as most areas were controlled by a tribe that dictated what was necessary within their territories (Benkari 2017; von Richthofen 2015). Traditional Omani neighborhoods favored compact houses, a recognized shaded communal outdoor gathering space known as a Sablah, and clear public to private transitions in terms of housing space (Edwards et al. 2006). The streets and connections were accessible to all (as neighbors were of the tribe) and so they were tailored to the specific needs of the community. After the Omani renaissance of 1970 with the introduction of a new Sultan, the government's involvement in developing the country increased significantly, and centralized top-down systems became the dominant planning practice.

The greatest legal change to the city structure was a land allocation system introduced in the 1980s, that aided in tribe mixing and led to the sprawl we see today. Royal Decree 81/84- the Government Land Entitlement System effective since 1984 stated that all Omani male citizens could apply for and receive free $600 \mathrm{sqm}$ housing plots at the age of 23 . The plots were randomly allocated, which demographically intertwined neighborhoods of Muscat (Heim et al. 2018). These plots were also regulated by building laws that mainly allowed for single-family detached houses known as Villas. The original conception of these homes did not provide "privacy", a commodity Omani families respected (since they no longer lived within their tribes) as well as being a constituent of Sharia law (Hakim 2008; Othman et al. 2015), and therefore the addition of a large boundary wall encompassing one's plot to substitute for this need became inevitable.

The granting of free land to young men in their early $20 \mathrm{~s}$ did not take into account whether they were financially stable or in need of their own living space. Consequently, the unpredictable rate and area of individual housing growth within the city put the municipality under pressure to catch up with the development of the public spaces, because landowners began building their homes before the implementation of infrastructure and basic services such as roads, water, gas, electricity lines, streetlights, phone lines and any sort of public gathering space (Al Shueili 2015; von Richthofen 2015). Currently neighborhoods are typically dotted with vacant lots, there are dirt roads and water trucks have to deliver weekly water supplies. Independently of the Municipality, residents in the area have taken over vacant areas and set up makeshift playgrounds (see Fig. 1), parking lots, parks, seating areas and garbage collection points. Furthermore, a specific density threshold was never strictly established by the municipality, in order to determine when and in what order to provide infrastructure.

A booming economy and a rising concentration of inhabitants in the Capital of the Sultanate was followed with a decision enacted in 2008, that extended the system to female Omani nationals ('Women in OmanOmanuna Portal'; HRC-Universal Periodic Review 2015). Since the 1980s, Omani citizens have grown in population from around 40,000 to over 2 million (Oman Census 2010). Where once only half of the population was able to apply for land, that right has been extended to all Omani nationals. This added to the series of growths straining the system to keep up with zoning lands at a viable rate. The average waiting time to receive free land escalated from a few months to a decade. With public pressure on officials to create the next master plan of the city, this unsustainable growth is in the process of being tested and calibrated in the upcoming years. Many local experts criticized past decades of development as unsustainable and inefficient (Al Gharibi 2014; Nebel and Richthofen 2016), suggesting adjustments to the ongoing system or the introduction of new typologies that could contain the current sprawl and low densification.

\section{A public health issue}

The lottery land allocations in Muscat were furthermore planned by the Ministry of Housing and the Muscat Municipality in monofunctional residential zones, essentially creating a city of suburban qualities. Such planning 


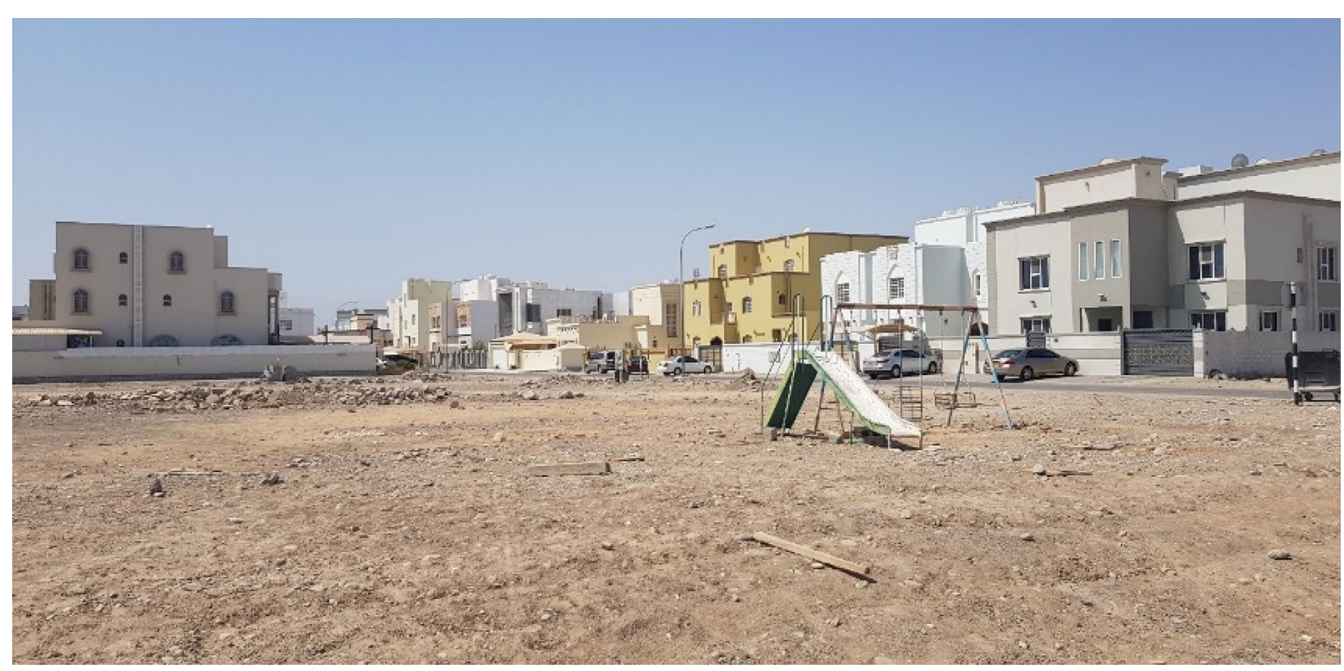

Fig. 1 The newest allocated neighborhood of Maabilah, pictured in 2019 by the paper's authors. The neighborhood is in the process of being built up with individual housing since 2005. The neighborhood amasses a space of $52 \mathrm{~km}^{2}$ with an average of 0.19 FAR, by the authors' calculations. The area is dotted with empty plots and $62 \%$ of built houses are yet to be connected to a paved road, let alone other basic infrastructure

practices have been the norm since the 1980 s, so that three generations of residents have grown up in isolated conditions with cars as the main access to most functions in their everyday life. The dependence of cars to move around the city is high, with public bus transportation not beginning until late 2014 and still not connecting neighborhoods well (Belwal 2017). Coupled with summer highs of $50^{\circ} \mathrm{C} / 122^{\circ} \mathrm{F}$ and the arid climate, the motivation for walking in Muscat is very low.

Cardiovascular disease is the number one cause of death, followed by obesity (WHO Regional Office for the Eastern Mediterranean 2017), with clear links to inactive lifestyles (Mabry 2018), and thus sedentarism has become a matter of public health. Authorities have since pushed an agenda of developing active healthy cities within the country (Ministry of Health Oman).

While a call for change in typologies and future land allocation is due, working with existing structures to boost neighborhood walkability is also an ongoing conversation amongst planning organizations of the city (de Siqueira et al. 2018; Mabry et al. 2014).

Besides the healthy benefits, walkable Cities are also recognized as more efficient in contributing to more compact growth and reducing land consumption (Newman et al. 2016). Further, increased walkability is associated with a decrease in the number of travels (Calthorpe and Van der Ryn 1986; Ewing and Cervero 2001) contributing to reduction of energy consumption and emissions (Wilson and Navarro 2007). Additionally, it has a significant impact on social aspects of the neighborhoods where they are in place (Lund 2002; Rogers et al. 2013) and helps to boost local economy (Pivo and Fisher
2011) turning neighborhoods more resilient and reducing inequity (Speck 2018). Therefore, although the focus of this study is the urgent contribution to address the call for curbing the growing levels of NCDs, turning Muscat into more walkable environment is in general a relevant agenda to increase its livability and to meet the United Nations SDGs.

Participation and human centered approaches to planning This research responds to objectives of Oman's Five Years Plan and TANFEEDH (planning proposals by the government), which focus on social and urban environmental issues (Supreme Council of Planning). Coming from social policy reports, the planning proposals envision "advanced social connections amongst the community to improve the feeling of togetherness and achieving participation". With its emphasis on the Comprehensive Social Development goal, together with the implementation of the National Strategy for Urban Development and the aim of Balanced Development among Governorates, these proposals pave the way for the vision authorities have for the Omani future.

Favorizing a focus on a more comprehensive approach "the plan shall be carried out to upgrade the various governorates to achieve similar performance levels among them in areas of education, health, social services, engendering work opportunities, development of infrastructure and public facilities services". By working closely with communities on site, this research has employed local knowledge and the potential of a more active and vibrant life of shared open spaces in neighborhoods of Muscat. We also intended to find out, using a bottom-up 
approach, whether communities would independently create solutions that parallel with the objectives set out by these governing bodies of Muscat.

Long-term planning on the national level has based its future vision for Oman in 2040 on participatory approaches, to achieve sustainable development by "absorbing the economic and social reality, [to] objectively outlook the future" (2040 Oman Vision 2019, pp. 2 ). Through the theme of People and Society, the vision recognizes the importance of having a society that can be involved in growth. The vision also recognizes wellbeing and social protection as priorities and reinforces the importance of empowering a civil society that participates effectively in sustainable development as one of its key factors (Oman 2040 Committees 2019).

Although Arnstein's ladder (1969) paved the way we think about participation in urban planning and beyond, emerging economic and political power differences between stakeholders create gaps, and limit the community's influence over outcomes. These gaps create the space for negotiation between agents of urban change and they can provide a flexible and more engaging model for participation such as collaborative design (Escobar 2018; Manzini 2015). These two concepts can be used to counteract the situational distrust and disconnect Omani citizens have towards the planning bodies (through years of miscommunication), as well as the contrary inherent belief that the governing bodies should oversee change and that they are the only ones able to provide such change. Engaging citizens in the decision-making process over the spatial development of their communities as well as allowing for a dialogue between the directly involved stakeholders is an emerging concept and method in the case of Oman, one that governing bodies are, at least theoretically speaking, willing to experience (2040 Committees Oman).

Finally, participatory approaches, such as collaborative design workshops, might also contribute to enhance the scope of walkability studies since many authors identified problems in the prevailing methods (Gebel et al. 2009, 2011; Hooper et al. 2020; Loh et al. 2020) where results of perceptual assessment and objective assessment don't necessarily overlap. Moreover, despite robust literature on the subject, the potential of co-design workshop is still underexplored in the field and a gap yet to be considered by reviews (Ding and Gebel 2012).

\section{Methodology: addressing walkability}

Having already established that the large monofunctional residential neighborhoods of Muscat are unpleasant to walk through, we set out to understand to what degree residents are nevertheless walking within their areas. As Oman is a Muslim country, planning practices dictate that a mosque needs to be present, and specifically that all residents should have a "neighborhood" mosque within a $400-500 \mathrm{~m}$ radius of their home. This radius, equivalent to a 5-min walk, also coincides with the pedestrian shed, i.e. the average distance in which walkable interactions are most likely (Mehaffy et al. 2010).

As Muslim men go to mosques to pray up to 5 times a day, these became the areas with the highest pedestrian usage in the neighborhoods of Muscat. When the residents were asked about the facilities to which they walked the most, we found that the mini grocery store and other amenities attached to the mosque attract some pedestrian activity. Preliminary results yielded the mosque as a walkable core exclusively for males, and the attached stores include the use of space possible for the female residents.

When analyzing pedestrians' ability or capacity of movement, there exist walkable barriers that affect the user outcomes. These barriers may be immaterial, such as cultural restrictions, or material, such as lack of pedestrian walkways. Our team therefore carried out two research approaches through:

1. A quantitative assessment on perceived walkability scale using a standard tool with residents of 8 neighborhoods;

2. Mapping the attributes of the walkability scheme on a 500-m radius study site, with the neighborhood mosque as the center. This was carried out in the same 8 areas.

These two research methods were meant to assess the perception of residents about their immediate surroundings (standard walkable scale survey) compared to the physical environments (analysis maps) and guide a subsequent quantitative research phase. The data generated a list of agreed-upon unfavorable/favorable situations, as well as pinpoint the necessary topics of discussions to residents and aid planners or regulation makers to execute informed design decisions. These studies were carried out by Urban Planning and Architectural Design students of the German University of Technology in Oman, who lived in the 8 project areas identified, with guidance by the paper's authors.

Originally, the focus of the survey was Omanis nationals, although no restriction in this regard was made. The interviewers (our students) were instructed to cover a geographical area and target mosque-goers and existing pedestrians in order to get a clearer response when asking walking-related questions. In addition, they were asked to make an equal distribution of female and male subjects, but no distinction of ages (although the survey did question one's birthyear). 
The quantitative survey was an updated and shortened version of the IPEN-NEWS survey on walkability (Kerr et al. 2015; Sallis and DeBourdeaudhuij 2012). The original survey was developed on the basis of multiple studies analyzing built environments and their relation to walkability, with a specific emphasis on the neighborhood level. For this study, the survey was adapted to local conditions (de Siqueira et al. 2018) in objectively measurable terms grouped into subscales that accessed attributes of density, land-use, street connectivity, pedestrian infrastructure, aesthetics and safety. The survey was equipped to include local services (such as the Mosque and Sablah) as well as being translated by the paper authors into Arabic. Of the attributes questioned, the original survey inquired about personal safety and crime. As bodily harm crime statistics in Oman are low and would not be easily validated and mapped out, the team therefore instead asked questions about road safety and neighborhood lighting situations for a spatial reference. Through the use of the application survey monkey, the students were given time to carry out the questionnaires in their respective neighborhoods.

Conversions of the questionnaire's elements into standardized mapping tools allowed us to make comparisons of perception and objective assessments, as well as one to one comparisons of the built environment

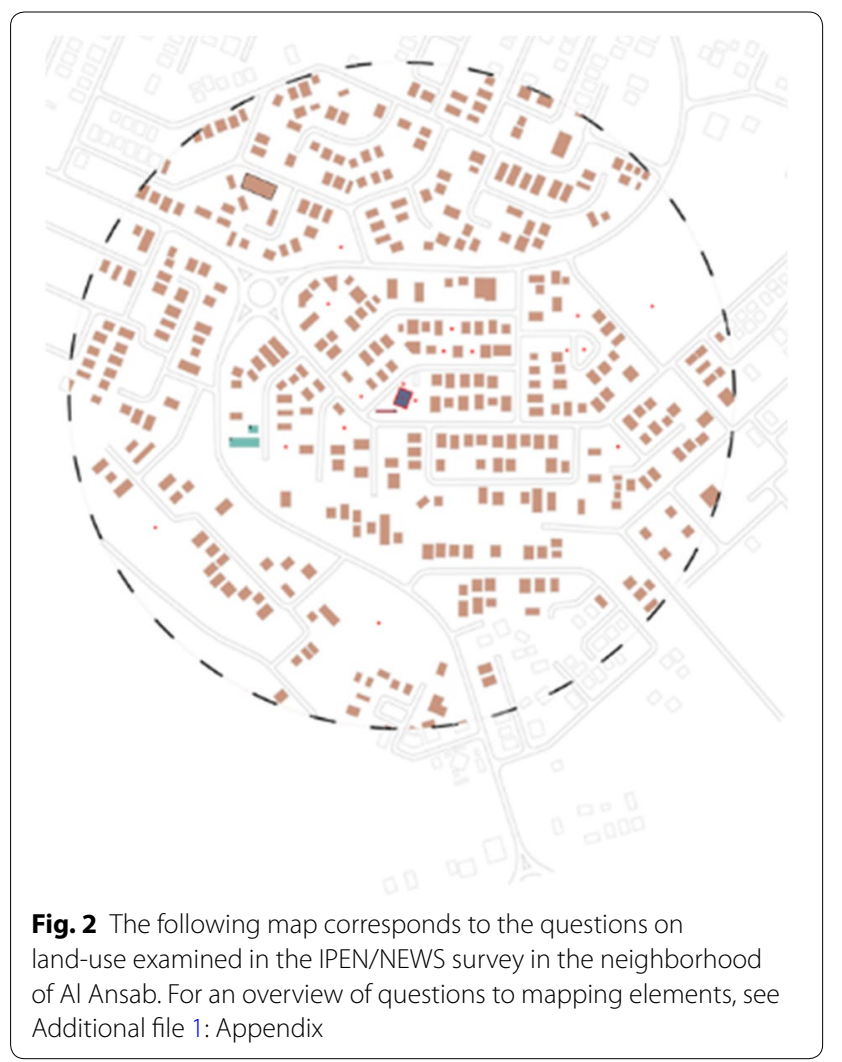

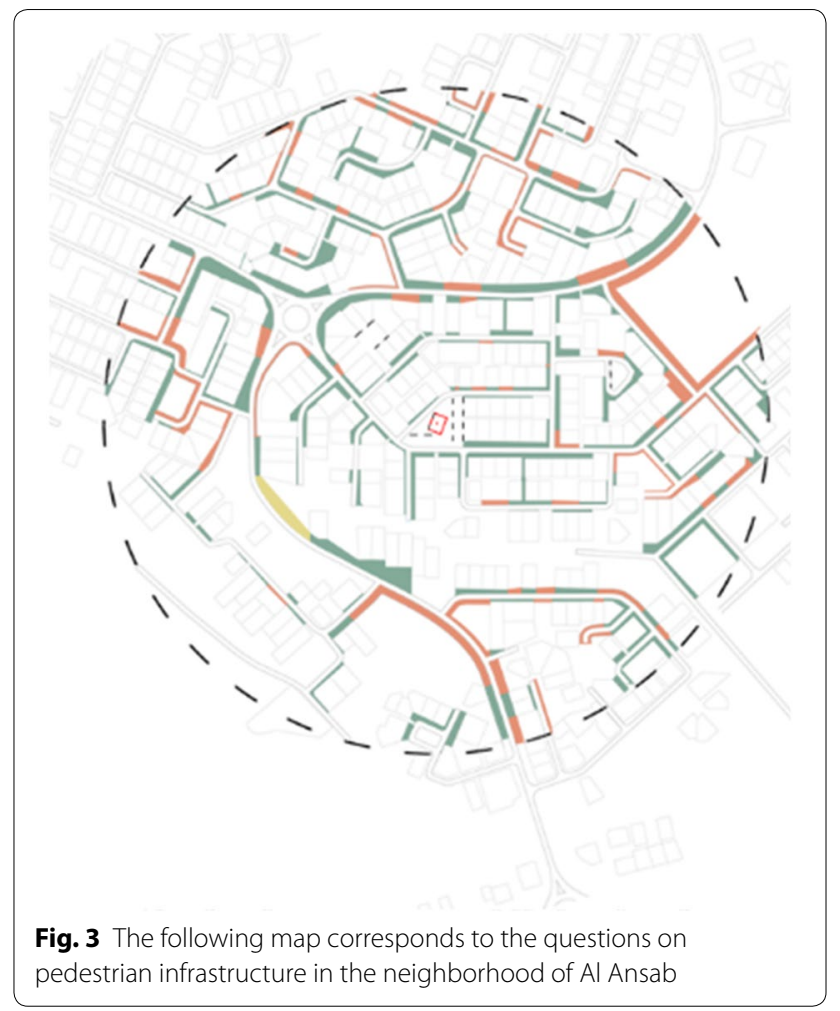

of the neighborhoods studied. The elements helped produce analysis maps of each studied location that were created by the students, where one could see the

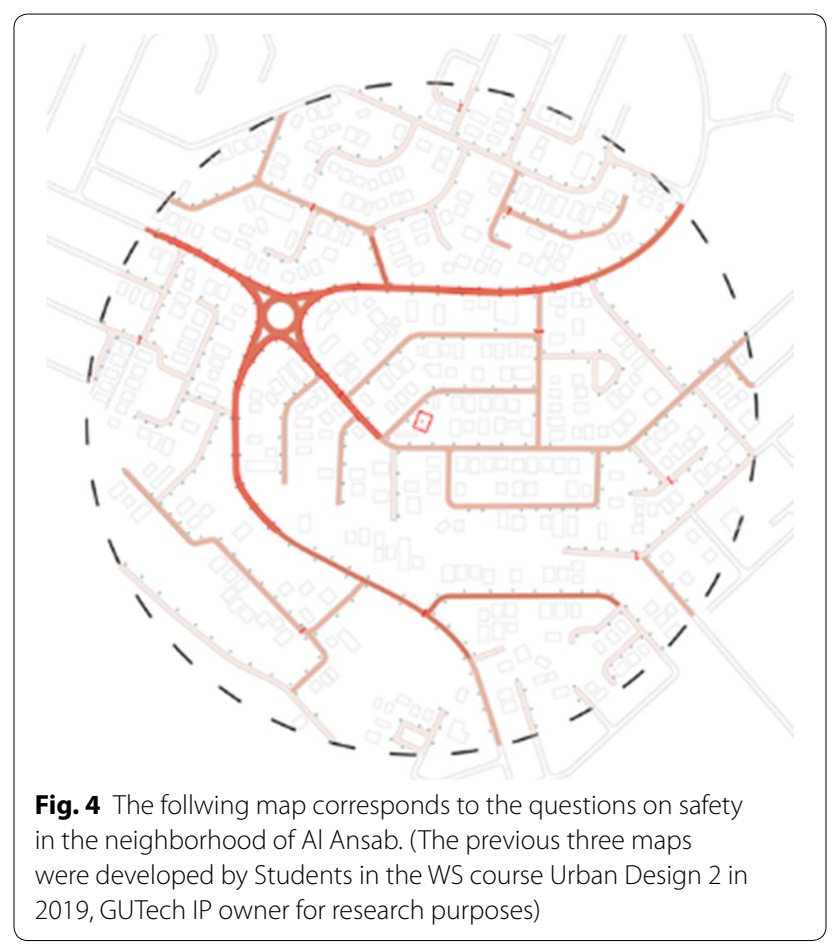


monofunctionality of a neighborhood, such as in Fig. 2, the lack of adequate paving, such as in Fig. 3, or areas in which the speed and traffic loads of cars seemed higher than others, as shown in Fig. 4. While most portrayals of attributes (such as Density) were easily translated onto a scale or specific symbol done in a quantitative process, the survey also included one question on Aesthetics and whether there were "beautiful areas in the neighborhood". In this specific case, the maps have room for student's subjective observations.

Rather than just sticking to the perception and portraying maps on the areas, we also conducted footfall counts and vehicle traffic analysis in order to look for the most active spots within a specific neighborhood, as well as to prove that our chosen areas of intervention accorded to the highest impact level and possible users.

For each of the 8 project areas analyzed, the research findings were condensed to 3-4 main conflicted attributes that would then be the basis of conversation and action points to bring to the residents during the codesigning charrette. For example, in the case of the neighborhood of Al Ansab (shown in the maps of Figs. 2, 3 and 4 above, and results of the IPEN-NEWS surveys diagramed in Fig. 5), the three attributes that stood out negatively in both perceptions and built environment were that of land-use mix (diversity), pedestrian infrastructure, and safety. Therefore, these three attributes were examined, discussed and conceptually re-designed in the community workshops held in the WOW project.

\section{The WOW project and city gaming}

The Where Oman Walks (WOW) project focuses on increasing the levels of pedestrian activity coupled with the activation of the public realm in Oman's residential areas. It aims to solve challenges caused by car-oriented development and to invoke conversations about spatial changes and the social innovation required to sustain

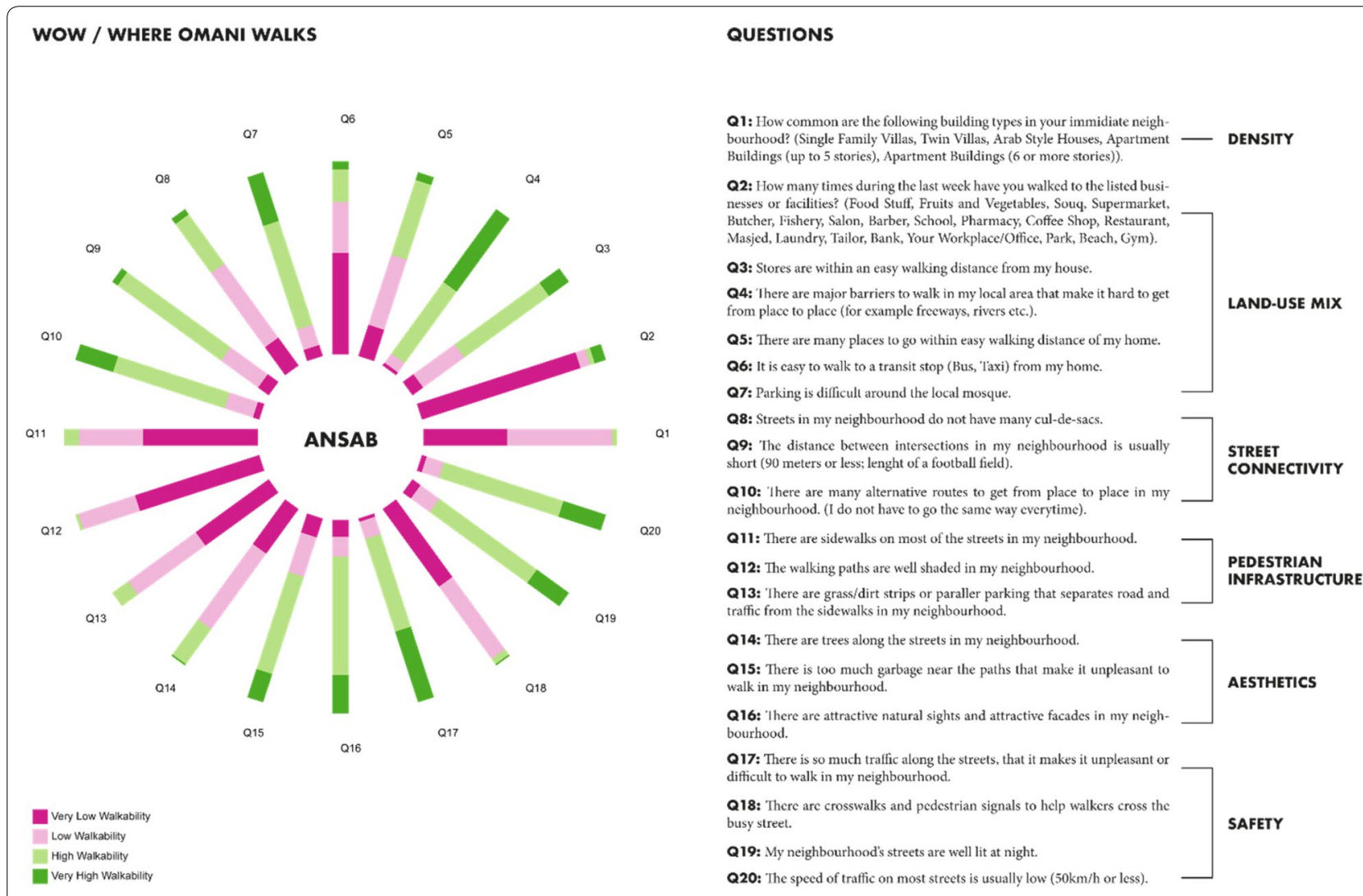

Gustavo de Siquiera, Marianne Sigl, Klaudia Dudzik

Fig. 5 Results of surveys on perceived walkable attributes in the neighborhood of Al Ansab in 2019 
that change. The project works by employing the local knowledge on cultural needs and networks coupled with a research-based understanding of the area.

The students, being residents familiar with the areas, were asked to set up workshops with their community and to recruit immediate residents surrounding the neighborhood mosque at a closer radius of around $160 \mathrm{~m}$ (covering an average of 27 houses). The workshops were applied at a more intimate radius as a "first step", for a manageable study attempt, with the intention of possibly growing to include the full 500-m radius in the future.

Due to cultural norms, the creation of these workshops had to be gender segregated. The invitations to such events happened through social media, invitations delivered door to door, pamphlets and word of mouth for harder to reach groups (females in general). The risk of bias due to the tendency of students interviewing people of their own family or their social groups was considered and avoided by door-to-door recruitment and direct invitations at the local mosque after midday prayers by flow sampling (helpful in inviting adult male subjects). As a last resource we employed snowballing to guarantee that females were represented, usually by approaching an active member of the community.

The workshops occurred on mosque grounds after the final prayers of the day (Ishaa) for males and throughout the day in open spaces or parks for females. The invitations were not limited, however, to the residents but frequently also included the local imam of the mosque [Such as was present in the workshop in $\mathrm{Al}$ Ansab (Fig. 6)], the business owner of the convenience store, municipality representatives and council members.

The gaming setup of the workshops was an attempt to integrate human-centered approaches into the future planning process in Muscat. It was developed in a broader scholarly discourse of collaborative design (Manzini 2015; Portugali and Stolk 2016; Tan 2014) responding to culturally sensitive demands identified locally by the residents, as well as aimed at responding to the objectives of the study such as spatially tackling the lack of physical activity in Oman. The design of the game treats each location as a complex context that should be examined in detail, and the solution should be case specific and user specific rather than general. Additional to understanding the basic correlations between people's behavior and the built environment, WOW provokes a negotiation process to overcome identified challenges and sparks initial discussions on self-governance.

\section{The game: introduction, open-end responses and spatial negotiation}

In order to introduce the participants to the aims of the workshop, the game moderators (our team) began with presenting our three main findings on the perceptions/ physical constraints of the area and had a quick discussion with the participants on their opinions of these findings. We also elaborated on general concepts of

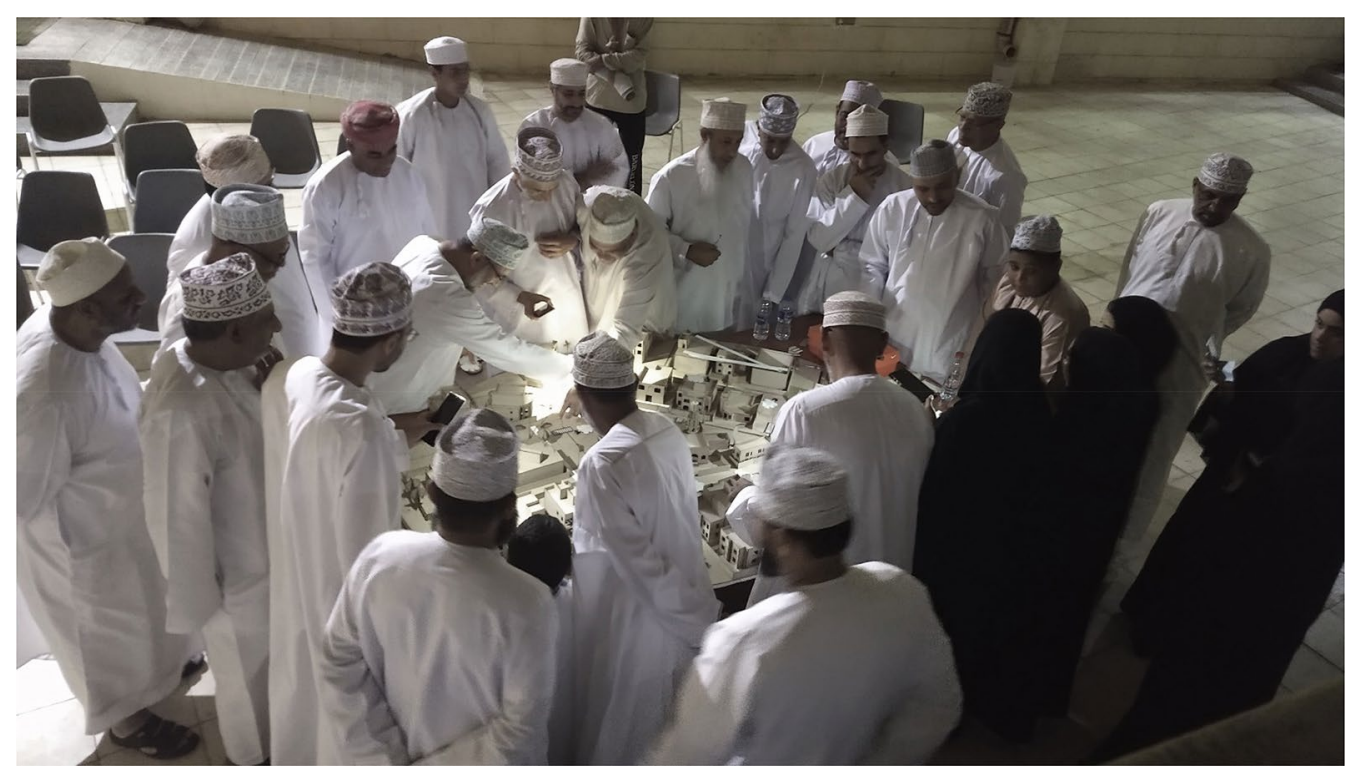

Fig. 6 Male workshop in the neighborhood of Al Ansab led by GUTech female students in 2019 within the boundary walls of the Ansar Heights Mosque - residents and the Imam discussing a paved alleyway and open spaces beside the mosque that is considered 'dangerous' as cars pass at high speed. Picture by the paper's authors 
walkability and Muscat's lack thereof, as well as its health implications.

While earlier surveys extracted resident's perceptions strictly following the schemes of the standard walkability scale, the workshops attempted to induce an open discussion in which case-specific information not covered by the quantitative assessments emerged.

Participants were subsequently given open-ended cue cards on which they were able to express good and bad aspects of their neighborhood (before the play), as well as interesting things they are missing and wish to have (after the conclusion of the negotiation). These were announced as possible extra information that authorities and designers could consider when working with an area, which we treated as "joker cards" - an out of the gaming norm card.

During the interactive part of the workshop (the negotiation), residents communicated with one another on the spaces in front of their homes and what could be done to improve walkability. These discussions were held on the gaming "interface" which was a 1:100 scaled replica model of their neighborhood. To meet the functional requirements of the game interface of the co-design workshop narrowing the subject area to the walkable core of $160 \mathrm{~m}$ radius (from $400 \mathrm{~m}$ ) was necessary; to create a 3D cardboard model on a scale that was comprehensible and easy to handle for all participants. That reduced once more the number of residents who were able to actively participate in the game, with an average of 21 participants per workshop (with two workshops done in each location), as only those residing in units represented in the interface were primarily leading the negotiations in the areas in front of their houses.

The attendees had the freedom to discuss the placement of urban elements such as trees, pedestrian walkways, zebra crossings, types of shading elements, etc., in the replica model; the actual homeowner had the final say about what went in front of their own home. The use of a large model and cutouts representing design elements was to allow residents with limited experiences to realistically assess the area they have. The negotiation of space directly in front of a resident's house was usually held by those personally affected by the space (neighbor to neighbor), with them offering design possibilities and reasonings for liking or disliking the ideas, while negotiations on public space or elements that affect the entire neighborhood were open for general discussions. Due to the segregated nature of the workshops, the male and female residents did not get to communicate with one another on their spatial negotiations.

These workshops lasted for up to $2 \mathrm{~h}$ and participants of all of the 8 project areas discussed various important topics that ranged from material to immaterial subjects and ways in which to deal with them. In Al Hail, a neighborhood land allocated and built up pre-2008, the residents took a step forward in discussions to begin a neighborhood committee that would deal with these issues and discuss amongst themselves ways to design and solve the problems in their areas. In many other workshops this was the first time neighbors had met and discussed with one another the area in front of their homes and certain barriers or problems they had when moving through and around the neighborhood. Recordings of these workshops were done through pictures of the events/design outcomes, as well as collections of suggestions by the public collected during informal conversations after the end of the game.

\section{Results}

The perceptions versus physical representations findings allow designers to renovate existing neighborhoods, to work with the most pressing matters according to its users, and to understand the recurrence of issues facing a specific area. Our findings brought in a range of responses in different setups; in terms of computable data, however, the NEWS surveys, analysis maps and cue cards were the only ones able to be put on a range of walkability effects, while the interventions made on the replica model were handled as a case-specific response to guide future interventions locally. The cue cards were open ended, and responses could be categoriesed into the attributal themes related to IPEN/NEWS with a new adition of social aspects, as shown in Fig. 7.

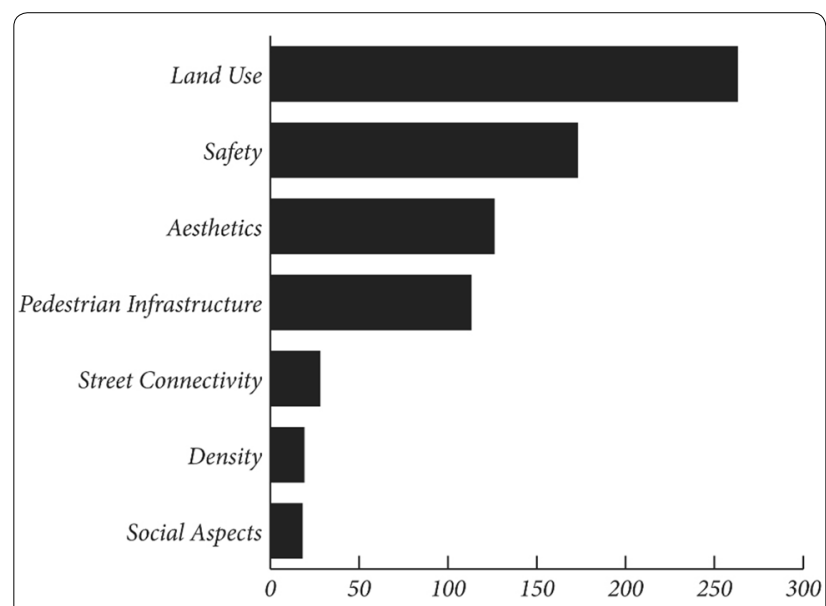

Fig. 7 Results of the open-ended surveys using cue cards ( $n=200$ approx.). The most relevant and spoken about attributes influencing walkability in the neighborhoods of Muscat 


\section{Cue cards}

Encompassing eight different neighborhood boundaries within the city of Muscat, the workshop attempted to further understand residents' perceptions towards their immediate surroundings. Through the use of cue cardsunder three distinct categories of good, bad and interesting things - the residents were able to give open-ended responses that were then coded accordingly to the IPEN attributes used previously in the surveys and maps, with the additional groupings of social aspects.

With a combined 236 participants (54\% female, $46 \%$ male) we found that overall throughout Muscat the topics most discussed in the cue cards related to land-use (34\%), compared to the least mentioned topics such as social aspects (2\%) and density (2\%). Safety was the second most mentioned topic at $22 \%$. pedestrian infrastructure and aesthetics were both referred to in around $15 \%$ of the cases. The cards were $12 \times 6 \mathrm{~cm}$, provided in red and blue as pictured in Fig. 8, and were continously available to the residents throughout the workshop meetings.

\section{The Good...}

Even though original mappings portrayed the monofunctional zoning of residential neighborhoods of Muscat, the diverse use of land was the topic that was most identified when looking into the Good parts of Muscat's neighborhood ( $41 \%$ of all responses). Furthermore, previous neighborhood surveys proved that residents did not or could not walk to amenities regularly. This could be explained by the recurring number of times different residents singled out one specific shop near to their neighborhoods. The residents were also not asked to specifically write about the good things about the neighborhood from a walking distance, which may suggest that the responses were at times based on car-ride perceptions.

Altogether commerce and education (34\%), mosques (26\%), and neighborhood gardens (18\%), were highly appreciated. Male residents of Muscat were most likely to point at the nearby services and mosques in their neighborhood as a "Good" detail, while women instead perceived educational facilities and gardens in the area as a positive. The service areas tend to be connected to or nearby the neighborhood mosque; through our workshops, and further discussions with the female residents,

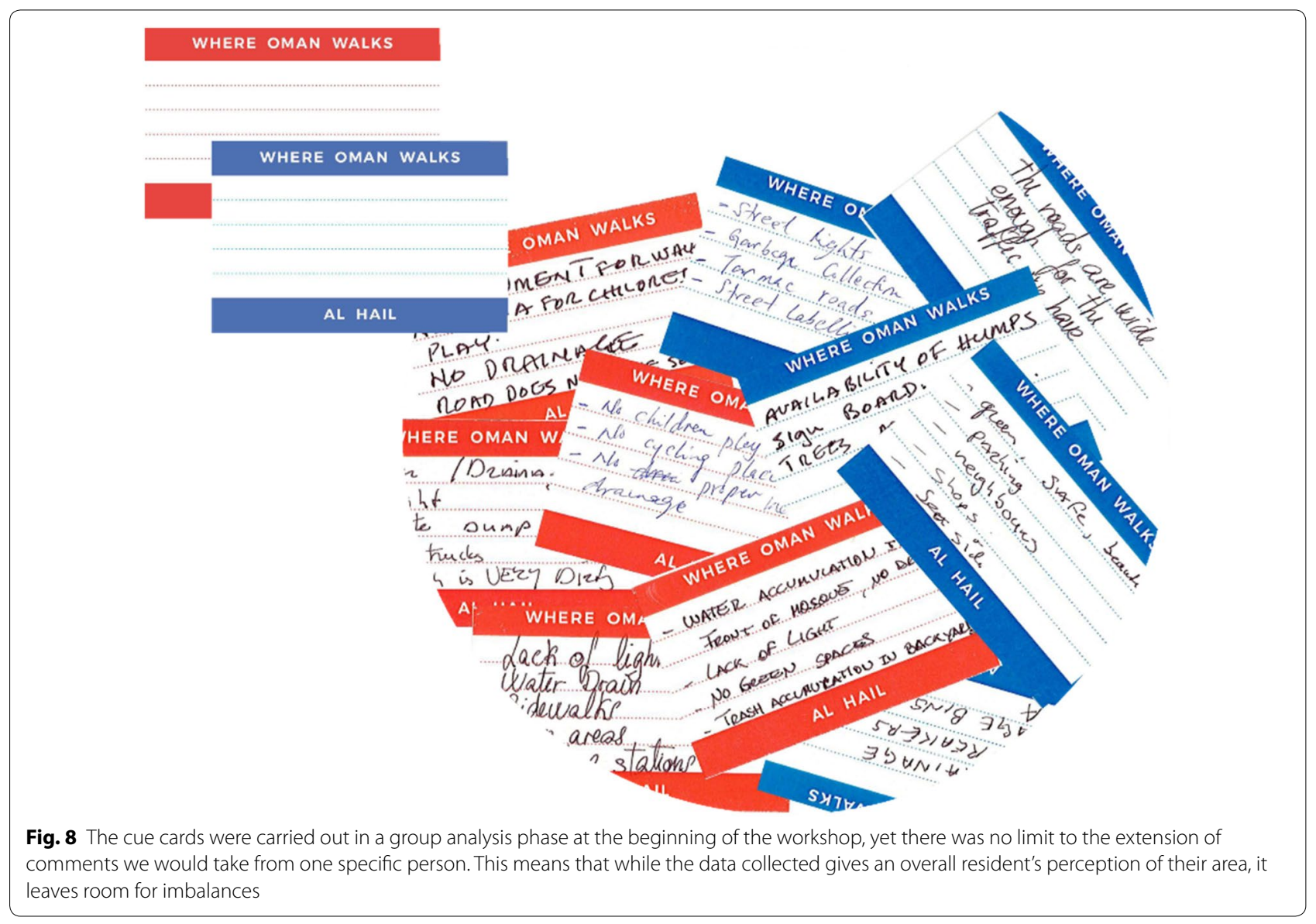


this was identified as a male-dominated space and in some ways not as inviting to women. This leads to the controversial essence of the mosque as the core of activities and economy of Muscat's neighborhoods, when half of its residents feel unwelcome or not properly involved in the area. Yet the mosque is still the most walked-to amenity in all neighborhoods, due to daily prayers.

Land-use was mentioned significantly in both the bad and good categories; it should be noted that while residents appreciated having a neighborhood mosque, educational facility or commercial point, they felt the land-use was inadequate structurally or spatially for parking their cars, as well as needing more functions within their immediate space.

\section{The Bad...}

While Oman has been in the top 20 to the top 50 ranks of the global peace index (IEP 2019) in the last 10 years, as well as experiencing low crime rates, the country has been acknowledged as an area with high road-related fatalities over the years. Road accidents are among the 10 most common causes of premature deaths in Oman (University of Washington 2010).

With that in mind, safety was the most identified "Bad" element of neighborhoods, eliciting $30 \%$ of all responses. When looking further into the results of safety, only $3 \%$ of safety-related responses were due to personal health. This came in the form of commenting on the abundance of stray dogs and rats in the area, and the long distance from and hence tardy response by Fire Departments in the area. In comparison, $62 \%$ of the residents identified traffic-safety issues as a major problem in their neighborhood. Complaints mostly included the speed of cars and unreliable road safety signs, as well as the poor conditions of the roads. An added 22\% referred to the missing or broken streetlights and, during more in-depth discussions at the workshops, neighborhood members revealed that the lack of lights have an adverse effect on possible driving styles.

Overall, 24\% directed negativity towards Land-use, and $21 \%$ towards pedestrian infrastructure. Social aspects, street connectivity and density were mentioned in less than $2 \%$ of recorded responses. The results of the Good cue cards differed based on gender, while men and women generally agreed on the Bad cue cards.

Although residents expressed an understanding as to how their built situation supported an inactive and thus unhealthy lifestyle, of the Bad cue cards only $13 \%$ of responses stated a need for pedestrian-friendly elements in their areas such as zebra crossings and better pedestrian sidewalks.

\section{... \& the Interesting}

Land-use, pedestrian infrastructure, and safety were the most evident elements the residents discussed when asked to introduce interesting things they would like to see in their immediate space. The responses connected accordingly with the earlier discussions on Good and Bad cue cards. Respectively more different amenities and shadings were requested in all neighborhood workshops carried out. Women identified female praying halls and gathering spaces as a need in the newer post-2008 neighborhoods (such as Al Maabilah and Al Ansab), while male participants leaned more to road related or functional additions.

\section{Replica model}

The mosque area was recognized by all participants as the most active but not necessarily the most pleasant at the same time. Unlike men who are using the space for gatherings and interactions after prayers, female participants perceive it as rather undesirable. "Men look at me" and "Ladies do not walk in front of the mosque" were the comments that altered the walking path in two directions during some workshops-while men would prefer to keep their activities close to the mosque, women tend to walk further from it, on the other side of the street. The question of privacy for men who were praying and women who were passing by was a conversation that was regularly discussed by neighbors. The Replica model allowed for spatial comments to be made that helped the team understand the unspoken rules of the area (as seen in Fig. 9, with one resident approaching the replica to discuss a specific spot in the neighbourhood).

Different areas had residents react to situational elements, such as a dip in a street that retains rainwater on one street in the neighborhood of Al Hail, potholes on the roads in front of the mosque at $\mathrm{Al}$ Mawaleh, or a specific spot with accumulating garbage in Al Ghubrah. Changes discussed ranged from official interventions needed by the municipality for repairs, to invoking a behavioral shift of neighbors on how they treated the outdoor space. Residents were quick to explain their likes and dislikes of possible urban elements-such as explaining the types of trees they approve of based on previous experiences when asked to place trees throughout the neighborhood, or their opinions of seating elements and why they would not approve of them in front of their homes (Al Hail). The model also made room for dialogues between individuals on their connected space-as in the case of neighboring houses in Al Azaiba that identified hedges on the sidewalk space in front of their homes that restricted movements of pedestrians, and how far different neighbors 


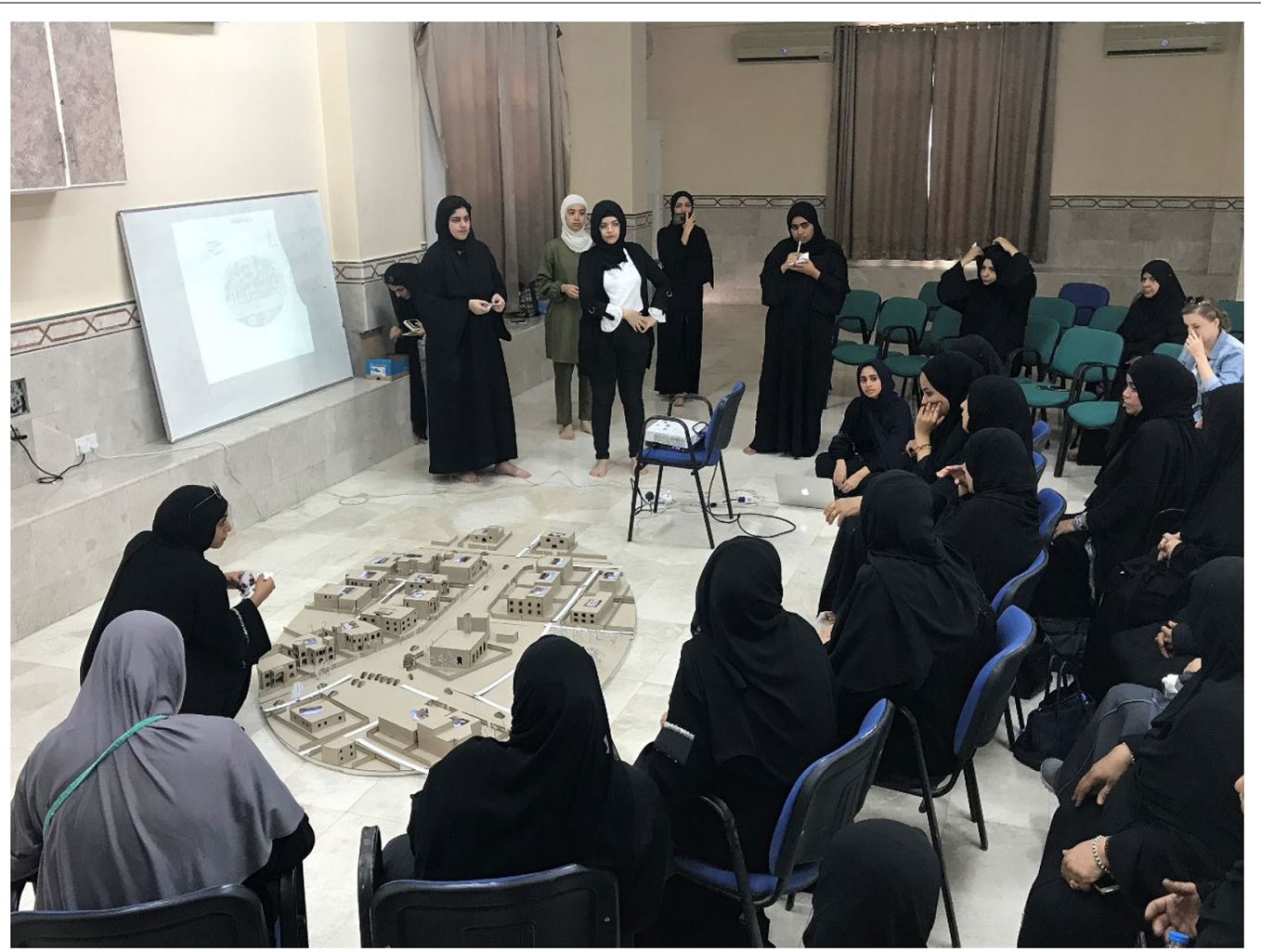

Fig. 9 Women's workshop about the Al Ghubrah neighborhood in 2019. Residents used the replica model to input urban elements such as sidewalks and zebra crossings, appropriately responding to the predetermined goals of walkability. They were also given the freedom to use 'comment cards' to address non-physical spatial cues and cultural norms of the area that could be considered when redesigning the area, as well as situations not forecasted by the planned workshop structure

were willing to cut back their hedges to provide the necessary space.

Through the activity of placing pedestrian infrastructure, sidewalks were almost always regarded as an infringement of privacy when placed too close to a house's boundary wall; through the workshops in all neighborhoods it was unanimously agreed the sidewalks should be as far away from their homes as possible. The proposed placements deviate from the designs by the planners of gated/pre-built communities of big developers throughout the capital (see Al Mouj and Muscat Hills settlements) and can inform possible preferences of the communities of future areas.

Through discussions, most homeowners were willing to give up some parking spaces on the side of the road to allow for sidewalks. At one point, one resident also voiced that she was not interested or willing to contribute to the possibility of a more walkable neighborhood as she did not see herself using it. The workshop discussions helped us identify possible users and agents that could help the realization of the project, as well as getting an overall census on the existing culture of the neighborhood community, and the willingness or need for change in these areas. The placement of elements on the replica model spatially showed us by how much these agents were willing to induce possible changes. We were able to collect the overall ideas at the end of each workshop in an area, and merge the proposals by the male and female participants into one "Wishlist" for the area portrayed in Fig. 10; with final "critical zones" in which new designs should be proposed highlighted in purple.

\section{Discussion}

Despite the Omanis being famed for their hospitality and laissez-faire attitude, we found that the residents were usually very reluctant to participate in the one-on-one surveys. Interviewers struggled to recruit subjects and to manage to complete questionnaires. In contrast, once the workshops started the level of discussions and commitment were regularly overwhelming.

A disadvantage of using a mosque as a walkable magnet in such Gulf cities is the exclusive use by male residents for praying, whereas women usually pray at home (when not out for work). Conversely, acting as a multifunctional walkable core, mosques offer an equal benefit to women, providing small multifunctional infrastructure emerging 


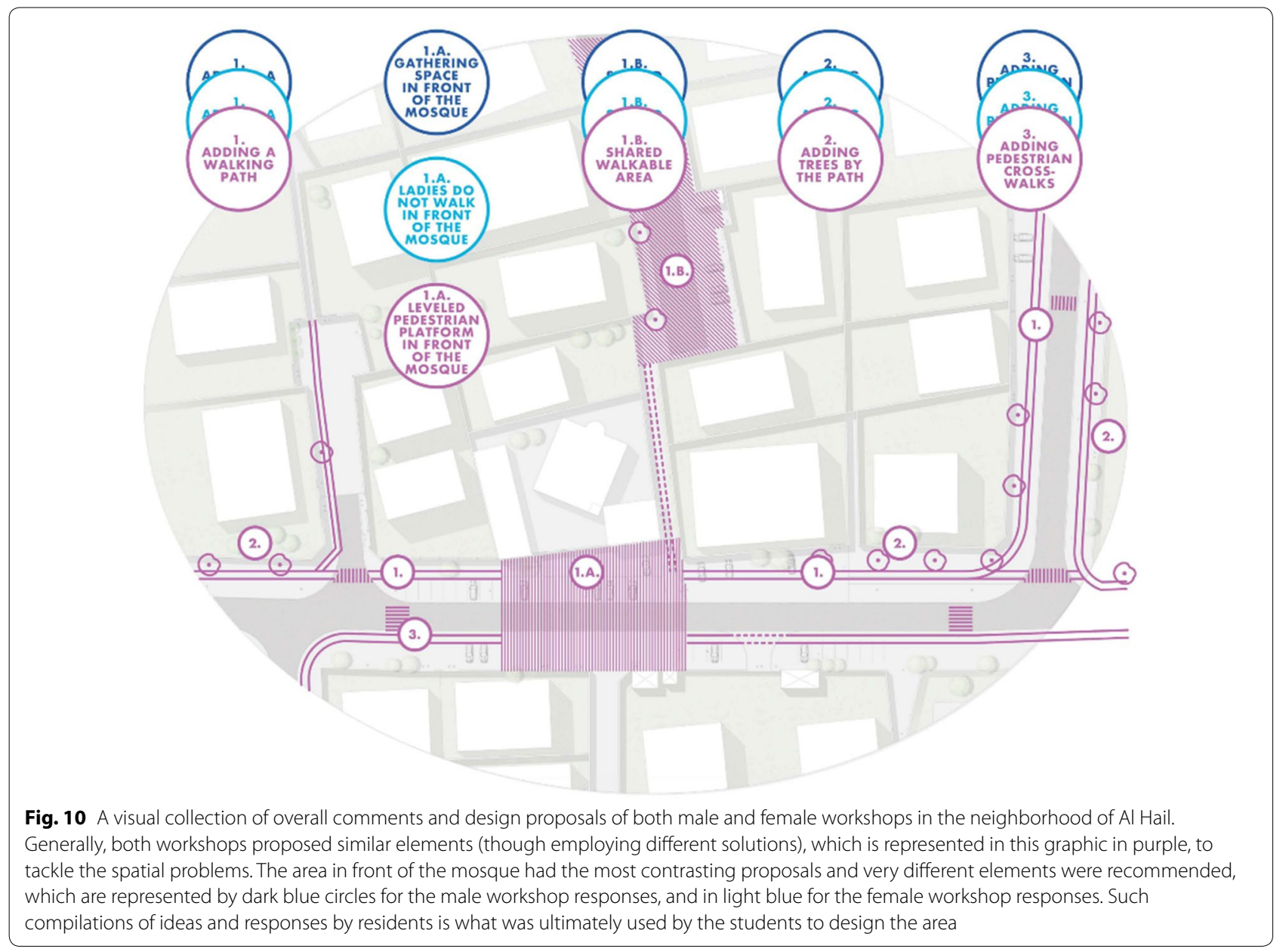

in the surroundings. Furthermore, it is the male population that is most affected by non-communicable diseases in Oman, as related to lack of physical activity (WHO 2014). In the use of such participatory tactics, local cultures and social rules play a role in what residents would be willing to design and discuss.

Nevertheless, other stakeholders (nearby residents, shop owners, etc.) were involved in the discussions and were able to state their visions based on their specific situation and to translate them to the more commonly shared parts of the public spaces. This ultimately gave the team an understanding of the culture and needs of the larger area of the neighborhood.

This study worked with perceptions on two levels. One, within a $500 \mathrm{~m}$ radius with a structured and walkingfocused survey, and two, within a more concentrated $180 \mathrm{~m}$ radius using open ended cue cards. As these tools were meant to help provide future designers of an overall concept from the residents within each neighborhood, a 1:1 comparison of their results was not strictly intended. However, when looking at the results side by side, we can see patterns evolving, particularly in topics relating to the pedestrian infrastructure and safety. These patterns emerged within the results themselves but were also higher in contrast between responses from females and males.

The gender-sensitive discussions that were held and written down on cue cards were self-evident in the workshops. In the process of placing urban elements into the replica model, the participants regularly brought up safety, cultural norms and religion, in regard to gender, when discussing their choice of action within a certain space. In the case of the neighborhood of Al Hail, when ideas of placing benches along the walkways leading to the neighborhood mosque were introduced, dissent against this by the participants were stated for the possibility of it deterring men from reaching the mosque by sitting down, or women sitting there and being watched. In these instances, discussing how to provide comfort as well as cultural appropriate walkways emerged between designers as well as the residents themselves. 
Another aspect of the cue cards is that the open ended quality did support the survey ideas; as the IPEN-NEWS surveys provided heavy positive weights to non-residential activities, good lighting, safe streets, and beautiful areas. These provisions were all marked in a positive light by the residents as well when using the cue cards, in a self-fulfilling manner.

\section{The future of walkability and participatory workshops in Muscat: recommendations to planning authorities}

This study deals mainly with existing built up neighborhoods of the sprawling city and how to deal with issues already existing. The suburban qualities of the neighborhoods of Muscat, of which three generations of Omanis have lived through, have been critically assessed throughout this paper. As the city has grown to reach it's municipal boarders, the emergence of newer neighborhoods is limited; However, the aspects of cultures and identities that have been studied and acknowledged in this paper can be seen as a necessary aspect to acknowledge when designing within or without the city.

When talking about participation and how to increase physical activity and public life within the residential neighborhoods in Muscat, the striking outcome of this project was the opportunity to discuss with locals (a) the problems communities face, (b) the provision of tools to allow these discussions to happen, and (c) co-creating concrete implementation plans. In approaching the neighbors, a side ambition was the possibility of activating a community to discuss and create changes. To some degree this was achieved when some neighbors understood minor shifts (such as the removal of plants blocking the walkway) that could help create a cohesive space for their neighbor. Yet these participative scenes were put forth to neighbors in a top down manner from our team, ultimately not reaching an activation point or moment of real life self-organization as would be accepted by Arnstein's Ladder (1969).

Furthermore, the study failed to include the expatriate communities, as the surveys and workshops were carried out in English and Arabic. Within Muscat, specific old neighborhoods carry high percentages of east Asian migrants who have formed communities and their own centers within their neighborhoods (Elham Annisa 2018; Mansour 2017).

Mediation processes represented by the spatial negotiation tools have been proven through this study as an efficient and very powerful mean to address spatial development challenges specific to local areas not embraced by the central government. The combination of qualitative open-ended questions following the similar structure of the quantitative survey and maps, on the other hand, revealed patterns helpful to guide general policies.
On the other hand, as stated before, the comparison of the two perceptive spatial tools results exceeded the scope of this paper and study, and were limited in their associations; which can be attributed to the way questions were asked and data was received, as well as the wavering goals of the different spatial tools used.

The surveys of IPEN-NEWS used to assess walkability do not include questions on the social aspects and cultural norms. Through contact with residents, we found that many existing ideologies restrict or dictate the manner in which a person can walk through a neighborhood. Furthermore, these ideologies directly relate to the types of urban elements a community is willing to accept in a design workshop, and suggest within the replica models provided. The takeaway from such a project is that planning in Oman should become much more gender sensitive. It needs to provide neighborhoods with gathering areas for women where they don't feel exposed, enabling them to congregate and to become more physically active. Furthermore, a sense of privacy is necessary according to the residents and this is something that the current spatial situation of most of the neighborhoods in this study does not provide.

More mixed-use developments will not only support physical activities but also generate the local economy, which can contribute to the necessity to overcome oil dependency. Strategies tackling traffic problems should be intensively integrated into neighborhood design to deal with wide-spread and well-grounded perceptions of hazardous road conditions. Yet as road safety was one of the most outstanding topics throughout all modes of analysis, it can be looked at as a direct correlation to a heavily car dependent state.

Comfortable pedestrian infrastructure with shading is a basic provision, which needs to be co-founded and administrated with the participation of the local community, the municipality and private companies.

Lastly, the direct surroundings of the local mosques should be regarded as a strategic area and treated as an activity node where more restrictive design regulations apply. Henceforward, the new walkable cores in the residential areas in Muscat will largely contribute to transforming it into a healthier city.

\section{Supplementary information}

Supplementary information accompanies this paper at https://doi. org/10.1186/s40410-020-00119-6.

Additional file 1. Appendix (1) showing the survey question to mapping elements. Other than prelimenary questions on gender and age, all questions were translated into a analysis elements and used to create maps, such as those presented in Figs. 2, 3, 4. This conversion and symbols used was done by the paper authors. 


\section{Acknowledgements}

We would like to express our gratitude to Felix Heusch, Marianne Sigl, Klaudia Dudzik, and all the students of the UD2 course 2018-2019, especially Mohammed Al Hatrushi, Maan Al Nabhani, Aya Al Mohammed, Habiba Al Harrassi, Rayyan al Rawas, Noor al Hinai, and Reem Al Habsi.

\section{Authors' contributions}

$A A B$ and GDS were both involved in all phases of the project, designing and conducting the research, collecting and analyzing data and writing the manuscript. All authors read and approved the final manuscript.

\section{Funding}

This article was produced within the framework of the G-18/19-003-GS. The Role of the Neighborhood Mosque in creating walkable cores in Muscat, A community based approach, internal funding program of the GUTech in Oman.

\section{Availability of data and materials}

This paper contains primary data collected by authors. Perceptual surveys, objective mapping and Community Co-design workshops where held in winter 2018 and 2019. Data might be made available upon requested and respecting confidentiality principles.

\section{Competing interests}

Not applicable.

Received: 10 May 2020 Accepted: 9 September 2020

Published online: 21 September 2020

\section{References}

2040 Oman Vision (2019) Moving forward with confidence: preliminary document

Al Gharibi H (2014) Urban growth from patchwork to sustainability case study: Muscat. TU berlin

Al Shueili KSM (2015) Towards a sustainable urban future in Oman: problem and process analysis (Muscat as a case study) [Degree of Doctor of Philosophy in Architecture, University of Glasgow, The glasgow school of Art]. core.ac.uk

Arnstein SR (1969) A ladder of citizen participation. J Am Inst Plann 35(4):216224. https://doi.org/10.1080/01944366908977225

Belwal R (2017) Public transportation in Oman: a strategic analysis. 20

Benkari N (2017) Urban development in Oman: an overview, pp 143-156. https://doi.org/10.2495/SDP170131

Bettencourt LMA (2013) The origins of scaling in cities. Science 340(6139):1438-1441. https://doi.org/10.1126/science.1235823

Bettencourt LMA, Lobo J, Helbing D, Kuhnert C, West GB (2007) Growth, innovation, scaling, and the pace of life in cities. Proc Natl Acad Sci 104(17):7301-7306. https://doi.org/10.1073/pnas.0610172104

Calthorpe P, Van der Ryn S (1986) Sustainable communities-a new design synthesis for cities, suburbs, and towns. In: Bulletin of science, technology \& society (Vol 6, Issue 4). SAGE Publications. https://doi. org/10.1177/027046768600600454

de Siqueira G, Al Balushi A, Petrovic O and Pasha P (2018) Where omanis walk? A comparison between the perception and the morphology of the built environment in different neighborhoods of muscat. In: AMPS proceedings series 13. Constructing an urban future. Abu Dhabi University, UAE. 18-19 March, 64-72

Ding D, Gebel K (2012) Built environment, physical activity, and obesity: what have we learned from reviewing the literature? Health Place 18(1):100105. https://doi.org/10.1016/j.healthplace.2011.08.021

Edwards B, Sibley M, Land P, Hakmi M (2006) Courtyard housing: past, present and future. Taylor \& Francis, New York

Elham Annisa S (2018, November 8) Understanding the housing needs of low-skilled Bangladeshi Migrants in Oman. N-AERUS 19. Housing and Human Settlements in a World of Change, Stuttgart. http://n-aerus.net/ wp/?page_id $=1116$

Escobar A (2018) Designs for the pluriverse: radical interdependence, autonomy, and the making of worlds. Duke University Press, Durham
Ewing R, Cervero R (2001) Travel and the built environment: a synthesis. Transp Res Rec J Transp Res Board 1780(1):87-114. https://doi. org/10.3141/1780-10

Flyvbjerg B (2003) Bringing power to planning research: one researcher's praxis story. J Plann Educ Res 21(4):353-366. https://doi.org/10.1177/07356 X021004002

Gebel K, Bauman A, Owen N (2009) Correlates of non-concordance between perceived and objective measures of walkability. Ann Behav Med 37(2):228-238. https://doi.org/10.1007/s12160-009-9098-3

Gebel K, Bauman AE, Sugiyama T, Owen N (2011) Mismatch between perceived and objectively assessed neighborhood walkability attributes: Prospective relationships with walking and weight gain. Health Place 17(2):519-524. https://doi.org/10.1016/j.healthplace.2010.12.008

Hakim BS (2008) Arabic Islamic cities: building and planning principles. Routledge, London

Heim B, Joosten M, Von Richthofen A, Rupp F (2018) Land-allocation and clanformation in modern residential developments in Oman. City Territory Archit. https://doi.org/10.1186/s40410-018-0084-6

Hooper P, Foster S, Bull F, Knuiman M, Christian H, Timperio A, Wood L, Trapp G, Boruff B, Francis J, Strange C, Badland H, Gunn L, Falconer R, Learnihan V, McCormack G, Sugiyama T, Giles-Corti B (2020) Living liveable? RESIDE's evaluation of the "Liveable Neighborhoods" planning policy on the health supportive behaviors and wellbeing of residents in Perth, Western Australia. SSM Popul Health 10(January):100538. https://doi.org/10.1016/j. ssmph.2020.100538

Human Rights Council-Working Group on the Universal Periodic Review (2015) National report submitted in accordance with paragraph 5 of the annex to Human Rights Council resolution 16/21*-Oman (GE.15-15245 (E); p. 23). United Nations General Assembly; A/HRC/WG.6/23/OMN/1. https://ap.ohchr.org/documents/alldocs.aspx?doc_id=25660

Kerr J, Emond JA, Badland H, Reis R, Sarmiento O, Carlson J, Sallis JF, Cerin E, Cain K, Conway T, Schofield G, Macfarlane DJ, Christiansen LB, Van Dyck D, Davey R, Aguinaga-Ontoso I, Salvo D, Sugiyama T, Owen N et al (2015) Perceived neighborhood environmental attributes associated with walking and cycling for transport among adult residents of 17 cities in 12 countries: the IPEN study. Environ Health Perspect 124(3):290-298. https ://doi.org/10.1289/ehp.1409466

Loh VHY, Veitch J, Salmon J, Cerin E, Mavoa S, Villanueva K, Timperio A (2020) Environmental mismatch: do associations between the built environment and physical activity among youth depend on concordance with perceptions? Int J Environ Res Public Health 17(4):1309. https://doi. org/10.3390/ijerph17041309

Lund H (2002) Pedestrian environments and sense of community. J Plann Educ Res 21(3):301-312. https://doi.org/10.1177/0739456X0202100307

Mabry R (2018) Urbanisation and physical activity in The GCC: a case study of Oman. http://eprints.Ise.ac.uk/86875/1/_Ise.ac.uk_storage_LIBRA RY_Secondary_libfile_shared_repository_Content_LSE\%20Middle\%20 East\%20Centre\%20Papers_2018_Mabry_Urbanisation\%20and\%20phy sical\%20activity.pdf

Mabry R, Owen N, Eakin E (2014) A national strategy for promoting physical activity in Oman: a call for action. Sultan Qaboos Univ Med J 14(2):170-175

Majid NHA, Shuichi H, Takagi N (2018) Cultural and climatic analysis: the basis of formulating compatible living environments in Oman. Asian J Behav Stud 3(9):87-100. https://doi.org/10.21834/ajbes.v3i9.64

Mansour S (2017) Spatial concentration patterns of South Asian low-skilled immigrants in Oman: a spatial analysis of residential geographies. Appl Geogr 88:118-129. https://doi.org/10.1016/j.apgeog.2017.09.006

Manzini E (2015) Design, when everybody designs: an introduction to design for social innovation (R. Coad, Trans.). The MIT Press

Mehaffy M, Porta S, Rofè Y, Salingaros N (2010) Urban nuclei and the geometry of streets: the'emergent neighborhoods' model. Urban Des Int 15(1):2246. https://doi.org/10.1057/udi.2009.26

Ministry of Health Oman (n.d.) MOH vision, mission and goals. https://www. moh.gov.om/en/-51. Accessed 20 Mar 2020

Nebel S, Richthofen A (2016) Urban Oman. LIT Verlag, Münster

Newman P, Kosonen L, Kenworthy J (2016) Theory of urban fabrics: planning the walking, transit/public transport and automobile/motor car cities for reduced car dependency. Town Plann Rev 87(4):429-458. https://doi. org/10.3828/tpr.2016.28 
Oman 2040 Committees (2019) National priorities [Ministerial]. Oman Vision 2040. https://www.2040.om/en/national-priorities/

Oman Census (2010) Census 2010 final results [Census]. General Census of Population, housing and establishments. https://www.ncsi.gov.om/ Elibrary/Pages/LibraryContentDetails.aspx?|temID=Z8IrPfD8tBHwm1U XWqoQRQ\%3d\%3d

Othman Z, Aird R, Buys L (2015) Privacy, modesty, hospitality, and the design of Muslim homes: a literature review. Front Archit Res 4(1):12-23. https:// doi.org/10.1016/j.foar.2014.12.001

Pivo G, Fisher JD (2011) The walkability premium in commercial real estate investments. Real Estate Econ 39(2):185-219. https://doi.org/10.111 1/j.1540-6229.2010.00296.x

Portugali J, Stolk E (eds) (2016) Complexity, cognition, urban planning and design: post-proceedings of the 2 nd delft international conference. Springer International Publishing. https://www.springer.com/gp/ book/9783319326511

Regional Office for the Eastern Mediterranean (2017) Country Cooperation Strategy for WHO and Oman 2018-2022 (No. 007). Wold Health Organization, Geneva, p 44

Rogers S, Gardner K, Carlson C (2013) Social capital and walkability as social aspects of sustainability. Sustainability 5(8):3473-3483. https://doi. org/10.3390/su5083473

Royal Decree 81/84—the Government Land Entitlement System, (testimony of Omani Government-Ministry of Housing). http://www.fao.org/faolex/ results/details/en/c/LEX-FAOC097884

Sallis J, DeBourdeaudhuij I (2012) IPEN project [Org]. IPEN. http://www.ipenp roject.org/index.html

Speck J (2018) Sell walkability on equity. In: Walkable city rules: 101 steps to making better places. Island Press/Center for Resource Economics. pp 8-9. https://doi.org/10.5822/978-1-61091-899-2_4

Supreme Council of Planning (nd) Tanfeedh handbook. National program for enhancing economic diversification. https://www.scp.gov.om/en/Page. aspx?|=37. Accessed 6 Apr 2020
Tan E (2014) Negotiation and design for the self-organizing city. TU Delft, Delft, p 456

The Institute for Economics \& Peace (IEP) (2019) Global Peace Index 2019, No 13; Global Peace Index, p 107. http://visionofhumanity.org/reports/

UN-HABITAT (2016) World cities report 2016: urbanization and developmentemerging futures | UN-Habitat. UN-HABITAT. https://unhabitat.org/world -cities-report

United Nations (2015) World urbanization prospects: the 2014 revision. United Nations, New York

University of Washington (2010) GDB profile: Oman. Health Metrics and Evaluation. http://www.healthdata.org/sites/default/files/files/country_profi les/GBD/ihme_gbd_country_report_oman.pdf

von Richthofen A (2015) Desert sprawl: rapid urbanisation: the transformation of the desert in Oman. Topos 93:96-101. https://doi.org/10.3929/ethza-010637913

WHO (2014) World Health Organization—noncommunicable diseases (NCD) Country profiles, Oman. http://www.who.int/nmh/countries/ omn_en.pdf?ua=1

Wilson A, Navarro R (2007) Environmental impacts of automobile travel reducing the transportation energy intensity of buildings

Women in Oman-Omanuna Portal (nd). https://omanportal.gov.om/wps/ portal/index/gov/inclusion/Women/nOman/!ut/p/a1/hc9Nb4JAEA bgX8OVmf0ort62IVhRioYGYS8NNutKAqwBKv58aeOIRu3c3snzJjOgIAPVFK fSFH1 pm6L6ycr7jDfEI28xLoV4JygJfeURSykP-AjyEeCDkfhfP9ENbEE9Z evJFTCcl8bTRcSTICANA_9FJBM6j71bsPyIJFKWBuF05THf51 fw5NAQI Kns7vfpXDY7JgyoVu91q1v3ux3Xh74_djMHHRyGwTXWmkq7X7Z28F7IY Lsesr8SjnV2XpTreis6eQHEWiN1/dl5/d5/LOIKQSEvUUt3SS80RUkhL2Vu/. Accessed 3 Apr 2020

\section{Publisher's Note}

Springer Nature remains neutral with regard to jurisdictional claims in published maps and institutional affiliations.

\section{Submit your manuscript to a SpringerOpen ${ }^{\circ}$ journal and benefit from:}

- Convenient online submission

- Rigorous peer review

- Open access: articles freely available online

- High visibility within the field

- Retaining the copyright to your article

Submit your next manuscript at $\boldsymbol{\nabla}$ springeropen.com 